\title{
Health promoting hospitals: A case study in Iran
}

Maryam Azarnoosh ${ }^{1}$, Mohammad Amiri ${ }^{2}$, Leila Riahi ${ }^{3}$, Ahmad Khosravi $^{4}$, Shima Naderi ${ }^{5 *}$

1. Department of English Language Teaching, Islamic Azad University, Semnan Branch, Semnan, Iran

2. School of Public Health, Shahroud University of Medical Sciences, Shahroud, Iran

3. Department of Health Services Management, Science and research branch, Islamic Azad University (IAU), Tehran, Iran

4. Center for Health Related Social and Behavioral Sciences Research, Shahroud University of Medical Sciences, Shahroud, Iran

5. Islamic Azad University, Semnan Branch, Semnan, Iran

*Corresponding author:Tel: +98 9124732536 Fax: -

Address: Department of Health Services Management, Semnan Branch, Islamic Azad University, Semnan, Iran

E-mail: shima.naderi68@gmail.com

Received; 2015/07/5 revised; 2015/08/1 accepted; 2015/10/22

\section{Abstract}

Introduction: Hospitals are the best ground for providing health promotion and prevention services besides health care services. This study aimed to determine the impact of establishing standards of health promoting hospitals on hospitals' indicators in one of the public hospitals of Iran.

Materials and methods: This research was a case-control study that included Fatemieh (case group) and Khatam-Al-Anbia (control group) hospitals. The standards of health promoting hospitals were established as independent variables in the case hospital. The collected data were related to the indicators of neonatal mortality, cardiopulmonary resuscitation (CPR), patient satisfaction and patient education in both hospitals in the second half of 1391(20122013) and the first half of 1392(2013). Then, SPSS version 16 was used to analyze the data through Chi-Square and $t$ tests and the results were displayed as comparing tables.

Results: With regard to establishing standards of health promoting hospitals in the case hospital the total score of these standards was 72.26 \pm 4.1 . The results indicated that establishing health promoting standards did not affect the neonatal mortality rate while it significantly affected success of cardiopulmonary resuscitation, patient satisfaction and the mean scores of patient education $(\mathrm{P}=0.001)$.

Conclusion: Preliminary results after establishing standards of health promoting hospitals represented positive effects in the case hospital and these standards led to improvement of some indicators.

Keywords: Health promotion, Health promoting hospital, Cardiopulmonary resuscitation, Patient satisfaction

\section{Introduction}

Health is one of the main concerns of most governments and global changes have created new challenges in health care systems, especially in hospitals (1). Hospitals are the most important places that provide health services; and health promotion services are the future landscapes of hospital services in health care systems. Thus it is necessary to change attitudes towards the role and capabilities of hospitals in becoming health promoting structures (2).By joining health care hospitals it will be possible to provide health promotion in a society (3). The main 
goal of hospitals is to provide health services for patients at the highest level (4) and health promotion services are one of the essential parts of the treatment chain providing clinical services(5). However, in our country, hospitals only play the traditional role of diagnosis and treatment, and how to provide many of health promotion services are not well defined. Thus, novel ideas are required to eliminate this situation to maximize the use of available facilities in supplying and improving the health of the society leading to desired and continuous results (2). This aim can be achieved by establishing health promoting hospitals. WHO codified the health promotion standards in five fundamental aspects: Management Policy, Patient Assessment, Patient Information and Intervention, Promoting a Healthy Work place and Continuity and Cooperation(6), that focus on four areas including health promotion of patients, health promotion of staff and change the organization to a place devoted to health and health promotion of society (1).Standards of health promoting hospitals focus on hospital systems and the processes to create a healthy organization (7) in which all strategies work together and in accordance with each other in order to be effective (8). Health promoting hospitals are committed to applying health promotion in daily activities (9(and focus on patients' and their relatives' needs through intensive informing, communication and activities to provide better opportunities for patient care (10). One of the most important goals of health promoting hospitals is providing contexts for change in quality management in hospitals (11). The establishment of health promotion standards in hospitals leads to efficiency promotion and effectiveness in hospitals (10), increase of satisfaction and life quality of patients and staff (9), decreased treatment complication, frequent hospitalizations and reduction of treatment costs (1), and it improves health condition of organizations in the competitive health market (10). In addition, health promoting hospitals are more successful in employing, attracting and retaining staff (9); consequently, health promotion services decrease absenteeism rate and improve creativity and quality of work (2). The obtained results from some studies in the world show that implementation of health promotion activities in hospitals have many advantages including improved quality of services (4), improved clinical outcomes after treatment(12), decreased mortality, reduction of surgical complications, increased patients' satisfaction, improved life style, reduction in hospitalization of patients and decreased costs of treatment(5) and quality improvement of health care and increased welfare of the staff and patients(7). Although results of the same published studies are not available in Iran, Didarloo et al, based on their study, indicated that health promoting hospitals deal with supplying physical, mental and social needs of the people as well as overall needs of the hospital staff in confronting physical and mental stresses. They also try to internalize the health promotion and prevention concept among the staff, empower patients in hospital and interact appropriately with the society (1). Due to the importance of health promotion activities in hospitals, and regarding the novelty of the subject and lack of similar researches in Iran, this study aimed to determine the effect of establishing standards of health promotion hospitals on hospital indicators in Iran.

\section{Materials and Methods}

This is a case-control study conducted in 1392(2013) which includes Fatemieh (case group) and Khatam-Al-Anbia(control group) hospitals. Fatemieh hospital is affiliated to Shahroud University of Medical Sciences and Khatam-Al-Anbia is affiliate to Islamic Azad University of Shahroud. The standards of health promoting hospitals were established as independent variables in the case hospital. Khatam-Al-Anbia, regarded as the control 
group, was similar to the case hospital in terms of the number of beds, daily admission mean, mean of referring time to emergency ward and some other indicators. The research population included all of the staff in the case hospital $(\mathrm{N}=330)$, and all of the hospitalized patients and newborns in both hospitals. The sampling method used for hospital staff was stratified random sampling $(\mathrm{n}=170)$ and for hospitalized patients and newborns were census.

There is an official form in hospital admission unit with some questions about satisfaction of using information in medical records for research objectives and other purposes. It should be filled when patient is admitting by her/himself. If patient can not to fill this (because of disability, anesthesia or other reasons), it should be fill by her/his representative. It is explained clearly that participation in researches is free. This satisfaction form is designed by management team and quality improvement team in hospital. Researchers used only information in agree patient's medical records and they pledged to use information only for this research without naming. Furthermore, the aim of study was explained to staffs who were asked to fill health promoting hospital's questionnaire after provide the introduction letter from research department of Shahroud University of Medical Sciences. It was cleared that participation is free for staff too.

Fatemieh hospital, chosen as the case group, was the selected hospital in clinical governance plan and it has the first grade in hospital accreditation. Most of the quality improvement programs were implemented in this hospital and many hospital indicators were assessed. Due to time limitation and availability of data for indicators of neonatal mortality, cardiopulmonary resuscitation, patient satisfaction and patient education, they were considered as dependent variables. Standard forms of death record for newborns were used in order to collect data related to neonatal mortality indicator, and hospital forms were used for collecting data related to indicators of successful cardiopulmonary, patient satisfaction and patient education. Also, questionnaire of establishing Health Promoting Hospitals (HPH) standards (13) was used to evaluate standards of health promoting hospitals, the validity and reliability of which was confirmed by the Ministry of Health and Medical Education and its Cronbach'alpha was 0.89. The questionnaire consisted of 40 questions in five areas as follows: management policy (nine items), patient assessment (seven items), patient information and interventions (six items), promoting a healthy work place (ten items) and continuity and cooperation (eight items). The required data was collected in two intervals of the second half of 1391(2012-2013) (before intervention) and the first half of 1392(2013) (after intervention). The data related to effectiveness indicators (i.e., neonatal mortality, successful cardiopulmonary resuscitation, patient satisfaction and patient education) were fed into SPSS version 16 and were finally analyzed by Chi-square and T-tests.

\section{Results}

Overall, half of the infants who died were girls $(50 \%)$, the mean weight of infants who died was877.65 \pm 1518.00 and their mean age was $3.7 \pm 3.92$. $60.71 \%$ of accouchement of mothers in died infants was caesarean. Respiratory distress syndrome (25\%) and asphyxia (7.14\%) were the most important causes of neonatal mortality. In the case hospital, most cardiopulmonary resuscitations were done $(43.39 \%)$ at night shifts and more than half of the cardiopulmonary resuscitations $(61.32 \%)$ were successful. In the case hospital, the results showed no significant relation between neonatal mortality and establishing HPH standards $(\mathrm{P}=0.07)$.

Data analysis through the Chi-Square test indicated a significant relation between success of cardiopulmonary resuscitation indicator and establishment of $\mathrm{HPH}$ 
standards $(\mathrm{P}=0.001)$, in a way after establishing these standards, success percentage of cardiopulmonary resuscitation indicator was increased, while this indicator decreased in the control hospital (Table 1).

Table1. The effect of establishing standards of health promoting hospitals on cardiopulmonary resuscitation indicator.

\begin{tabular}{llccc}
\hline Time & Hospital & Successful CPR & Failed CPR & P value \\
\hline Before intervention & Case & $46(56.1)$ & $36(43.9)$ & 0.001 \\
& Control & $11(22.4)$ & $38(77.6)$ & \\
\hline After intervention & Case & $65(61.3)$ & $41(38.7)$ & 0.001 \\
& Control & $6(15)$ & $34(85)$ & \\
\hline
\end{tabular}

Data are shown as number and percent.

Data analysis through the Chi-Square test indicated a significant relation between patient satisfaction before and after the intervention, in a way after the intervention patient satisfaction was increased $(\mathrm{P}=0.001)$ (Table 2).

Table 2. The effect of establishing standards of health promoting hospitals on patient satisfaction indicator.

\begin{tabular}{lccc}
\hline Patient satisfaction & Before intervention & After intervention & P value \\
\hline Good & 2.5 & 48.8 & 0.001 \\
Medium & 83.8 & 51.2 & 0.001 \\
Weak & 13.8 & 0 & 0.001 \\
\hline
\end{tabular}

Data are shown as percent.

The scores of the educations offered to patients before and after the intervention are displayed in Table 3. The results of the T-test showed a significant difference between the mean scores of patient education before and after the establishment of standards of health promoting hospitals $(\mathrm{P}=0.001)$ so that the mean scores of the patients education after the establishment of standards was prominently higher (Table 3 ).

Table 3. The effect of establishing standards of health promoting hospitals on patient education indicator.

\begin{tabular}{lccc}
\hline Variable & Before intervention & After intervention & P value \\
\hline On arrival education & $1.5 \pm 0.97$ & $2.8 \pm 0.49$ & 0.001 \\
During hospitalization education & $1.85 \pm 1.1$ & $3.6 \pm 0.67$ & 0.001 \\
On discharge education & $0.85 \pm 0.73$ & $1.8 \pm 0.42$ & 0.001 \\
\hline
\end{tabular}

The total score of HPH standards in the case hospital was $72.26 \pm 4$.1. The mean scores of the five evaluated standards were as follows: management policy $14.6 \pm 1.35$, patient assessment $13.4 \pm 0.09$, information and patient interventions $11.86 \pm 0.5$, healthy workplace $17.6 \pm 1.6$, and continuity and cooperation $14.8 \pm 1.9$. While in the control hospital, the total score obtained for HPH standards was $16.26 \pm 7.5$, and mean scores were as below: in management policy $3 \pm 1.5$, patient assessment $5.26 \pm 2.7$, information and patient interventions $4.06 \pm 2.1$, healthy workplace $2.6 \pm 2.4$, and continuity and cooperation $1.3 \pm 1.3$. The results of the t-test showed a significant difference between the two hospitals with regard to the effect of $\mathrm{HPH}$ standards $(\mathrm{P}=0.001)$. The mean scores in all five areas of HPH standards were significantly higher in the case hospital after intervention in comparison to the control group (Table 4). 
Table 4. The mean score of standards of health promoting hospitals in the case and control hospital.

\begin{tabular}{llccc}
\hline Standards & Hospital & Mean \pm S.D & T test & P value \\
\hline Management policy & Case & $14.6 \pm 1.35$ & -22.149 & 0.001 \\
& Control & $3 \pm 1.5$ & & \\
\hline Patient assessment & Case & $13.4 \pm 0.9$ & -11.111 & 0.001 \\
& Control & $5.26 \pm 2.7$ & & \\
\hline Information and patient interventions & Case & $11.86 \pm 0.5$ & -13.641 & 0.001 \\
& Control & $4.06 \pm 2.1$ & & \\
\hline Healthy workplace & Case & $17.6 \pm 1.6$ & -19.745 & 0.001 \\
& Control & $2.6 \pm 2.4$ & & \\
\hline Continuity and cooperation & Case & $14.8 \pm 1.9$ & -22.245 & 0.001 \\
& Control & $1.3 \pm 1.3$ & & \\
\hline Total & Case & $72.26 \pm 4.1$ & -25.288 & 0.001 \\
& control & $16.26 \pm 7.5$ & & \\
\hline
\end{tabular}

\section{Discussion}

Findings of this study showed that in Fatemieh hospital there was no significant relation between establishing $\mathrm{HPH}$ standards and indicator of neonatal mortality, but a significant relation was observed between successes of cardiopulmonary resuscitation, patient satisfaction and patient education and establishing the mentioned standards. In addition there was no significant relation between establishing health promotion standards with neonatal mortality index in the case hospital. However, Tonnesen et al. (5) stated that health promotion services in hospitals resulted in decreased mortality, which is not consistent with the results of the present study. Perhaps one of the reasons of not observing changes in this indicator was the effect of variables other than HPH standards. It is worth noting that the effect of quality improvement interventions on some hospital indicators requires more time and it must be measured in longer intervals. In this study, more than half of the infants who died weighted less than $1500 \mathrm{~g}$, which is similar to the results of Zamani et al (14), BeskAbadi et al (15) and ZamaniKiasari et al (15). Also, in the first half of 1392(2013) the infants that died were mostly born by caesarean, which is in agreement with the results of Amani et al (17) and Nayyeri et al (18). The results showed that most of the infants who died were pre-mature babies, which is a finding similar to the results of Nayyeri et al (18). The effect of low-weight and pre-maturity on neonatal mortality is mostly approved in literature. Respiratory distress syndrome, asphyxia, sepsis and infection had the highest rank among the causes of neonatal mortality in the present study, which is in line with findings of Amani et al (17), Nayyeri et al (18), Zamani et al (14), BeskAbadi et al (15) and Javanmardi et al (19). It must be considered that neonatal mortality is influenced by genetic factors, hepatobiliary diseases (type and severity of disease) and hospital factors, such as education and experience of personnel and available facilities to provide services. Establishing quality improvement programs and promotion of services can have an important role on prevention of hospital and changeable factors in a long period.

A significant relation was observed between success of cardiopulmonary resuscitation indicator and establishing HPH standards in the case hospital, so that success percentage of cardiopulmonary resuscitation after intervention was higher than before it. Success percentage of cardiopulmonary resuscitation in the case hospital is higher than the finding of Nasiripour et al (20). In Fatemieh hospital, night shift had the most percentage of cardiopulmonary resuscitation, which is in agreement with results of Nasiri pour et al (20) and Azimi et al (21). Also, the age range of cardiopulmonary resuscitated people in Fatemieh hospital was from birth to 91 years old, which is the highest one 
among the three studies of Nasiri pour et al (20), Azimi et al. (21), and Jaberi et al. (22). In the case hospital most of the cardiopulmonary resuscitation was done in neonatal intensive care unit, while in study of Setayesh et al (23) emergency ward had the highest percentage of cardiopulmonary resuscitation. The greatest cause of cardiopulmonary resuscitation in this study was related to pre-mature infants, while in the research of Sayfi et al. (24) cardiac diseases, in Azimi et al. (21) internal illnesses and in Jaberi et al. (22) nervous system problems were the most frequent causes of cardiopulmonary resuscitation. Since the main factors in success of cardiopulmonary resuscitation include patient age, type and severity of disease, conversance and resuscitation facilities, time of arrival and resuscitation, quality improvement of services can promote some changeable factors such as staff conversance, available facilities and start time of cardiopulmonary resuscitation.

The results showed that, in Fatemieh hospital patient satisfaction increased after the intervention which is similar to the results of Khowaja and colleagues (25) and Polluste and colleagues (14).

In this study, $82.5 \%$ of patients expressed that they received the necessary educations on disease management and the average rating of admission educations, during hospitalization and after discharge education was significantly higher after intervention. While in the research of Haynes (21) only one-third of the patients admitted that they have received educations necessary for their disease.

The results showed that, in the case hospital the total score of $\mathrm{HPH}$ standards was $72.26 \pm 4.1$ (out of 80 ), while this amount in Lin et al (26)was 95.06(out of 100), and the total score in hospitals studied by Groene et al (3) was 71.9 \pm 25 (out of 136). The score of our case hospital in establishing health promotion standards was less than Lin et al
(26), but higher than Gerone et al (3). Based on the results, a significant relation was observed between establishing HPH standards and the total scores in the case hospital $(\mathrm{P}=0.001)$; in fact, the mean score in each of the HPH standard areas was significantly higher for the case rather than the control hospital. The highest score in the case hospital belonged to healthy work place that is similar to the results of Lin et al (27) while in research of Lin et al. (26) and Groene et al (3) and Yaghoubi et al. (28) the highest score was that of information and patient interventions.

Lack of relevant studies, passing a short period of time from the beginning of the intervention and the researcher inability to control all of the intervening variables were the most important limitations of this project that made it difficult to comment firmly on the effect of these standards on all of the hospital indicators.

\section{Conclusion}

It is difficult to comment on long term or short term positive effects of establishing health promoting standards on all hospital indicators. But preliminary results after establishing the aforementioned standards in the case hospital implied that the establishment of these standards had more positive effects than what was found in the control hospital on the improvement of indicators. Thus, in order to improve health promotion activities in hospitals and to increase the members of international network of health promoting hospitals $(\mathrm{HPH})$, it is recommended to establish the standards of health promoting hospitals in all the hospitals throughout the country the

\section{Acknowledgements}

The authors would like to thank managers and staff of Fatemieh and Khatam-AlAnbia hospitals for their cooperation. 


\section{References}

1. Didarloo A, Shojaeizadeh D, Ahmadi B. [Health Promotion in Hospitals, the Challenges facing the Health Care System]. Health Work J. 2008; (2): 1927. (Persian)

2. Heydarnia M, Abachzadeh K, Damari B, Azargashb E, Vosoughmoghaddam A.[Study of Expert Opinion on Health Promotive Services for Patients at Hospitals Affiliated to ShahidBeheshti University of Medical science]. Pejouhandeh Res J. 2009; 14(4):18390. (Persian)

3. Groene $\mathrm{O}$, Aconso J, Klazinga N. Development and validation of WHO self-assessment for health promotion in hospitals: Result of a study in 38 hospitals in eight countries. Health Promot Int. 2010; (2):221-9.

4. Polluste K, Alop J, Groene O, Harm T, Merisalu E, Suurong L. Health Promoting Hospitals in Estonia: What are they doing differently? Health Promot Int. 2007; 22(4): 327-36.

5. Tonnesen H, Echristensen M, Groene O, Oriordan N, Simonelli F, Suurorg L, et al. An evaluation of model for the systematic documentation of hospital based health promotion activities: result from a multicentre study. BMC Health Services Res. 2007; 145 (7):1-8.

6. Ottawa Charter for Health Promotion.World Health Organization, Geneva. 1986.

7. Delobelle $\mathrm{P}$, Onya $\mathrm{H}$, Langa $\mathrm{C}$, Mashamba J, Mane Depoorter A. Global health promotion- advances in health promotion in Africa: Promoting Health through Hospitals. Int Union Health Promot Educat (IUHPE). 2010; 14 (2): 33-6.

8. Jackson S, Perkins F, Khandor E, Cordwell L, Homann S, Buasai S. Integrated Health Promotion Strategies: a contribution to tackling current and future health challenges. Health Promot Int. 2007; 21(1): 75-83.
9. Groene O, Garcia-Barbero M. Health promotion in hospitals: Evidence and quality management. J Educt 2005; 2(8):134-7.

10. Nikpajouh A, Samadi B. [The International network of health promoting hospitals and health services: integrating health promotion into hospitals and health servicesconcept, framework and organization]. Iran Prevent Health Promot Instit. 2010;8((4)942-9. (Persian)

11. Haynes C. Health promotion services for life style development within UK hospital-patient's experiences and views. BMC Public Health. 2008; 8:284-94.

12. Oppedal K, Nesvag S, Pedersen B, Skjotskift S, Arstad A, Ullaland S, et al. Health and need for health promotion in hospital patient. Eur J Public Health. 2010; 21(6):744-9.

13. Groene O. Implementation of Health Promotion in hospitals Self-Assessment Guide and Forms. WHO Regional Office for Europe. 2006.

14. Zamani R, Torki Y. [Incidence and Causes of Prenatal Mortality in Abhar Emdadi Hospital in 2010]. ZUMS J. 2013; 21(87):103-11. (Persian)

15. Boskabadi H, Parvini Z, Barati T, Moudi A. [Study of the causes and predisposing factors in neonatal mortality in Ghaem hospital (March 2009 to May 2010). Iran J Obstetr. 2013; 14(7):6-14. (Persian)

16. Zamani Kiasari A, Kabirzadeh A, MohseniSaravi B, Rezazadeh E, Khademlou M, Biazar T. [Rate and Causes of Prenatal Mortality in Imam Hospital, Sari 2007]. Iran J Obstetr Gynecol Infertil. 2009; 12(2)23-30. (Persian)

17. Amani F, Barak M, Aminisani N, Dehghan M. [Neonatal Mortality and Its Related Factors in Hospital of Ardabil]. J Ardabil Uni Med Sci. 2006; 5(4):305-10 . (Persian) 
18. Nayeri F, Amini E, OloomiYazdi Z, DehghanNaieri A. [evaluation of the cause and predisposing factors in neonatal mortality by using international coding diseases version 10 in Valiasr Hospital]. Iran J Pediatr. 2007; 17(1):22-6. (Persian)

19. Javanmardi Z, Beygy M, Ghodoosi A. [Investigating about the causes of neonates' death in the hospitals of Isfahan Province]. Sci J Forens Med. 2010; 15(4): 229-33. (Persian)

20. Nasiripour AA, Masoudi I, Fathi E. [The relationship of CPR success and time of patient's referring to emergency department]. J Milit Med. 2012; 14(1):21-5.(Persian)

21. Azimi B, Motaghi M. [The Study of the success of CPR Team in Besat Health \& Care hospital in Hamedan in the first six months of 2009]. Sci J Rescue Relief. 2011; 2(6):27-32. (Persian)

22. Jaberi Y, Changizian L, Mazlomzadeh S. [Predictors of Outcome in InHospital Cardio-Pulmonary Resuscitation]. ZUMS J. 2011; 19(75):48-57. (Persian)

23. Setayesh A, Arhami A, Farsi D, Hossein Nejad AR, Zare MA. [Evaluation of cardiopulmonary and cerebral resuscitation (CPCR) outcome in emergency department of
HazrratRasoul-e-Akram Hospital from June 2003 to April 2004]. Razi J Med Sci. 2006; 13(52):135-44. (Persian)

24. Saifi F,Sharifi F, stangi S, Esmaeili K. [Success rate of cardio-cerebral and education centers-Kermanshah University of Medical Sciences]. J Kermanshah Uni Med Sci. 2009; 14 (3):273-8. (Persian)

25. Khowaja AR, Mistry R, Agha A, Karmaliani R. Potential benefits and perceived need for health promoting hospitals in Pakistan: a healthcare stakeholder's perspective. J Pakistan Med Assoc. 2010; 60(4), 274-9.

26. Lin $Y$, Huang $H$, Tung $S$. The Organizational Diagnosis of Health Promoting Hospitals in Taiwan. Patient Educat Counsel J. 2009; (76): 248-53.

27. Lin YW, Lin YY. Health-promoting organization and organizational effectiveness of health promotion in hospitals: a national cross-sectional survey in Taiwan. Health Promotion International Advance Access published. Health Promot Intl. 2010;6(5):471-7.

28. Yaghoubi M, Javadi M. [Health promoting Hospitals in Iran: How it is]. J Educat and Health Promot. 2013; 2(41):451-8. (Persian) 